\title{
Analysis of Influence of Urban Spatial Morphologies on Thermal Microenvironment
}

\author{
Fei Meng*, Qiren Yu, Xinyue Yang \\ School of Surveying and Geo-Informatics, Shandong Jianzhu University, Ji'nan 250101, China
}

Received: 21 February 2020

Accepted: 21 July 2020

\begin{abstract}
In the process of urbanization, microclimate issues such as heat islands and haze caused by the unique spatial forms of cities have attracted increasing attention. In this study, we analyze the measured data of the city of Jinan at $10 \mathrm{a} . \mathrm{m}$. in the summer and the simulation results of ENVI-met to explore the urban morphological parameters (UMPs) at different spatial scales. The correlations between the urban thermal environment and various indicators of spatial form were studied. The results show that in the vertical direction, the 3D morphologies of vegetation and buildings have different ranges of influence on air temperature $\left(\mathrm{T}_{\mathrm{a}}\right)$. In the case of commercial land and a building height of lower than $12.5 \mathrm{~m}$, its temperature is mainly affected by the shadow of the building, and the floor area ratio (FAR) and cubic indexes are significantly negatively correlated with temperature. The spatial scale and grid resolution simulated by the model are critical in the study of the relationship between urban morphology and thermal environment. Among the seven UMPs, the FAR and cubic index are most affected by the spatial scale. In comparison, the SVF is less affected by the spatial scale.
\end{abstract}

Keywords: urban spatial morphology, correlation analysis, spatial scale, urban thermal microenvironment

\section{Introduction}

With the increasing global climate change and urban heat island effects, high-temperature urban disasters have occurred frequently in various parts of the world in recent years. These have had significant negative impacts on the health and social economy of urban residents and have become one of the most important meteorological disasters experienced by cities [1, 2]. The world today, especially developing countries, is experiencing an unprecedented wave of urbanization. China's urbanization rate was $10.6 \%$ in 1949 and reached $58.5 \%$ in 2017. Rapid urbanization has changed

*e-mail: lzhmf@sdjzu.edu.cn the surfaces and spatial structures of cities through increased building height, reduced green coverage, and compact urban forms [3, 4]. As a result, the heat balance has been destroyed $[5,6]$, exacerbating the heat island effect [7], which produces a series of urban problems. Among these, the deteriorating thermal environment of urban spaces has become one of the most significant features of climate change in modern cities worldwide, and poses a serious threat to urban air quality, energy consumption, and public health [8-10].

Urban spatial morphology most directly reflects the link between urban systems and environmental changes. The impervious urban surface, extracted via remote sensing, and the characteristics of constructed buildings, such as building height, building volume, building coverage ratio (BCR), floor area ratio 
(FAR), and street space, are directly related to the urban microclimate (such as temperature and wind environment) and are often used as indicative factors to characterize the urban heat island effect [11]. In addition, the sky view factor (SVF) of urban street space is highly correlated with the urban heat island effect. The smaller the SVF, the greater the probability and intensity of the urban heat island effect [1214]. In terms of $3 D$ urban landscape index, the $3 D$ compactness index, distribution uniformity index, space crowded degree (SCD), and SVF have high correlations with the intensity of urban heat islands [15-16]. Zhao et al. [17] obtained mesoscale urban morphological parameters (UMPs) based on remote sensing data, and used urban abundance, vegetation fraction, and FAR to describe the urban morphology. Vegetation fraction and BCR were found to have a key impact on the surface thermal environment. Based on the measurement technology and geographic information system method, Hove et al. [18] divided the sample area into different urban forms and types and determined the influence of urban geometric characteristics such as $\mathrm{BCR}$, green coverage ratio(GCR), average building height and SVF on local climate and thermal comfort. Giridharan et al. [19] used in-situ measured data to determine that the urban heat island effect increased with SVF. When the SVF exceeded 0.3, the change in the urban heat island was small. Ali-Toudert et al. [20] used the 3D climate model in ENVI-met to simulate the changes in the urban thermal environment and found that appropriate street aspect ratios can significantly improve the street-level microclimate. Berger et al. [21] used remote sensing technology to compare the influences of 2D and 3D UMPs on the surface thermal environment, and found that vegetation fraction and BCR had the highest correlations with the thermal environment with correlation coefficients of 0.79 and -0.79 , respectively. Tong et al. [22] used measured data and geographic information system (GIS) technology to study the influences of UMPs, such as GCR and BCR, on the temperature in Tianjin. It was found that the average temperature increased with building height and reduction in street width. Existing studies on 3D urban temperatures and structures need to be strengthened. In particular, research cases using $3 \mathrm{D}$ temperatures and UMPs are rare.

The objective of this study is focused on the relationships between temperature and urban morphological indicators at different heights, and to explore the influence of urban internal spatial morphology on the thermal environment. Urban morphological indicators from 2D and 3D perspectives at different spatial scales were used in the context of urban temperature study. The data and methods used to achieve the above goal are presented in Section Material and Methods. The accuracy of the model is evaluated in Section Model Accuracy Assessment. Thereafter, from the perspectives of spatial dependencies (Section Spatial Dependencies of UMP-T Relationship) and dependencies pertaining to land use type and scales (Section Land Use-type Dependencies of UMPTa Relationships), and typical residential land, the relationships between the UMPs and air temperature $\left(\mathrm{T}_{\mathrm{a}}\right)$ are discussed. The findings of this investigation are presented in Section Conclusions.

\section{Material and Methods}

\section{Study Area}

Jinan is located at $116^{\circ} 11^{\prime}-117^{\circ} 58^{\prime} \mathrm{E}, 36^{\circ} 01^{\prime}-37^{\circ} 32^{\prime} \mathrm{N}$, to the south of the Yellow river and to the north of Taishan Mountain. It is the economic, political and cultural centre of Shandong Province, with a population of 7.46 million and an area of $7,998 \mathrm{~km}^{2}$ in 2018, of which agricultural land, construction land, forest land, grazing and pasture land, waters and other land types account for $44.2 \%, 22.4 \%, 10.5 \%, 7.1 \%$, $6.3 \%$ and $6.3 \%$, respectively [23]. The mean annual temperature is $14^{\circ} \mathrm{C}$, and the average mean precipitation $650-700 \mathrm{~mm}$. The natural vegetation is evergreen coniferous and deciduous broadleaf forest, which are mainly distributed in the southern mountainous areas of the city. It belongs to the temperate monsoon climate region and is a typical four-season city. In summer, the outdoor environment is hot and stuffy, and the heat island effect is evident. The study area is located in the Jinan High-Tech Zone with an area of $1.8 \mathrm{~km} \times 2.6 \mathrm{~km}$ (Fig. 1). The green space in this area is distributed on both sides of the road, forming a checkerboard pattern, with a greening rate of $40 \%$. The main roads in the study area are perpendicular to the prevailing wind direction in Jinan, and there is no tall building at the intersection, which is convenient to provide natural ventilation for the dominant wind direction. The selected area includes a variety of land use types such as residential land, commercial land and green space. The urban land is complex, and it is one of the commercial activity areas with obvious heat island effect in Jinan, which is typical and representative. Therefore, the results of this study are also applicable to other areas of Jinan City.

\section{Data Pre-Processing}

To obtain quantitative information, such as building height, accurately, the image control points are evenly distributed in the study area by connecting the Continuously Operating Reference Stations (CORS) of Shandong province with global positioning system (GPS) technology. The unmanned aerial vehicle (UAV) platform uses Phantom 4pro, equipped with a 20-megapixel Complementary Metal Oxide Semiconductor sensor, uses the UAV tilt photography technology to obtain the orthophoto map of the study area and Pix4D and Smart 3D for orthophoto stitching. It establishes the digital surface model (DSM) and reallife 3D models of the study area. The digital elevation 


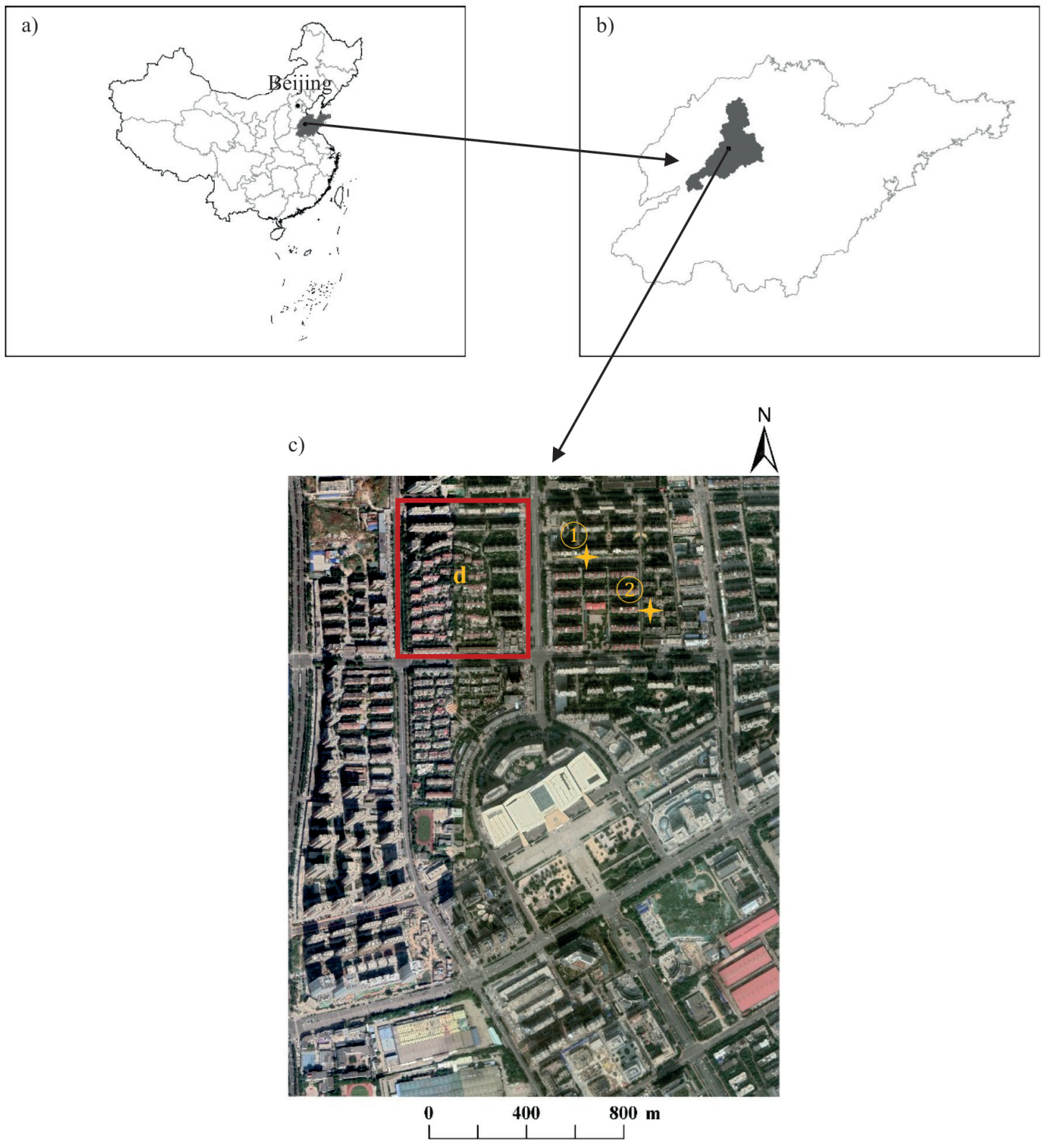

Fig. 1. Study area and location of Jinan: a) location of Shandong Province in China; b) location of Jinan; c) Study area of Jinan, where d) is a typical residential land area,; (1) and (2) are field monitoring points.

model (DEM) of the study area is incorporated to calculate the heights of buildings and vegetation and to obtain information, such as road width and water area. Based on the above data, the ENVI-met model of the study area was established and the values of $T_{a}$ at different heights were simulated. The meteorological data was measured using a handheld weather station, Kestrel 5500. The measurement points were located in different areas of the surface of the study area. Monitoring point 1 was located under a tree and monitoring point 2 was located by the side of the road.

Using the Spearman's correlation analysis, the correlations between the UMPs and thermal environment were calculated. To study the scale relationship between the UMPs and urban thermal environment, and obtain enough samples, the study area was divided into $9 \mathrm{~m} \times 9 \mathrm{~m}, 15 \mathrm{~m} \times 15 \mathrm{~m}, 21 \mathrm{~m} \times 21 \mathrm{~m}$, $30 \mathrm{~m} \times 30 \mathrm{~m}, 51 \mathrm{~m} \times 51 \mathrm{~m}$, and $102 \mathrm{~m} \times 102 \mathrm{~m}$ spatial statistical units in the GIS software. The relevant data, such as $T_{a}$ and surface coverage, were included in the GIS to construct a multi-scale research database.

Urban morphological parameters are an effective way to measure the urban spatial form. In the present study, seven parameters commonly used in urban morphological research were selected: BCR, FAR, GCR, SCD [21, 24], cubic index, vegetation fraction, and SVF (Table 1) [25]. The surface coverage and other related data were integrated in ArcGIS, and the information of the buildings and vegetation of each statistical unit was calculated. The UMPs of each unit were then calculated as the basis for the subsequent 
Table 1. Summary of 2D and 3D UMPs considered in present study.

\begin{tabular}{|c|c|c|}
\hline UMPs & $\begin{array}{l}\text { Abbrevia- } \\
\text { tion }\end{array}$ & Description \\
\hline \multicolumn{3}{|r|}{$2 \mathrm{D}$} \\
\hline $\begin{array}{l}\text { Building coverage } \\
\text { ratio }\end{array}$ & $\mathrm{BA}(\mathrm{B})$ & $\begin{array}{l}\text { Ratio of building area to total block area. Reflects the vacancy rate and building density within a } \\
\text { certain land use range. }\end{array}$ \\
\hline $\begin{array}{l}\text { Green coverage } \\
\text { ratio }\end{array}$ & $\mathrm{RA}(\mathrm{G})$ & Ratio of vegetation area to total block area. Reflects the ground greening of the site. \\
\hline Vegetation fraction & VF & Ratio of vegetation projection area to total block area. Reflects the ground greening of the site. \\
\hline Floor area ratio & FAR & $\begin{array}{l}\text { Ratio of total floor area of the building to the area of the land on which it is located. An index to } \\
\text { measure the intensity of land development. }\end{array}$ \\
\hline \multicolumn{3}{|r|}{$3 \mathrm{D}$} \\
\hline Cubic index & $\mathrm{CI}$ & $\begin{array}{l}\text { Ratio of building volume to total block area. Reflects the degree of utilization of the sky above the } \\
\text { city per area of the city unit. }\end{array}$ \\
\hline $\begin{array}{l}\text { Space crowded } \\
\text { degree }\end{array}$ & $\mathrm{SCD}$ & $\begin{array}{l}\text { Ratio of the sum of building volumes to the product of the highest building height and total block } \\
\text { area. Reflects the distribution density of the building in the 3D space. The larger the crowding } \\
\text { value, the lower is the openness. }\end{array}$ \\
\hline Sky view factor & SVF & $\begin{array}{l}\text { Proportion of visible sky within a given reference circle. Used to measure the extent of 3D open } \\
\text { space. The geometric space parameter that reflects the degree of openness of urban space to the } \\
\text { sky. The larger the value, the higher is the visibility of the sky. }\end{array}$ \\
\hline
\end{tabular}

study of the spatial relationship between urban form and urban thermal environment.

\section{Microclimate Model ENVI-Met}

The 3D non-static fluid model, ENVI-met version 4.4.3, was used to simulate the urban thermal environment from the $3 \mathrm{D}$ level by simulating the dynamic process of building surface-plant-atmosphere interaction on the microscopic scale of the city. The main characteristic parameters in the study area, such as buildings, vegetation, and surface properties, were all placed in the main 3D model [26]. The distribution of temperature and calculation of relative humidity were based on the advection diffusion equation. The processes of turbulence and airflow exchange were based on two additional K- $\varepsilon$ governing equations from Mellor and Yamada [27].

Navier-Stokes equations:

$$
\begin{aligned}
& \frac{\partial \mathrm{u}}{\partial \mathrm{t}}+\mathrm{u}_{\mathrm{i}} \frac{\partial \mathrm{u}}{\partial \mathrm{x}_{\mathrm{i}}}=-\frac{\partial \mathrm{p}^{\prime}}{\partial \mathrm{x}}+\mathrm{K}_{\mathrm{m}}\left(\frac{\partial^{2} \mathrm{u}}{\partial \mathrm{x}_{\mathrm{i}}^{2}}\right)+\mathrm{f}\left(\mathrm{v}-\mathrm{v}_{\mathrm{g}}\right)-\mathrm{S}_{\mathrm{u}} \\
& \frac{\partial \mathrm{v}}{\partial \mathrm{t}}+\mathrm{u}_{\mathrm{i}} \frac{\partial \mathrm{v}}{\partial \mathrm{x}_{\mathrm{i}}}=-\frac{\partial \mathrm{p}^{\prime}}{\partial \mathrm{y}}+\mathrm{K}_{\mathrm{m}}\left(\frac{\partial^{2} \mathrm{v}}{\partial \mathrm{x}_{\mathrm{i}}^{2}}\right)+\mathrm{f}\left(\mathrm{u}-\mathrm{u}_{\mathrm{g}}\right)-\mathrm{S}_{\mathrm{v}} \\
& \frac{\partial \mathrm{w}}{\partial \mathrm{t}}+\mathrm{u}_{\mathrm{i}} \frac{\partial \mathrm{w}}{\partial \mathrm{x}_{\mathrm{i}}}=-\frac{\partial \mathrm{p}^{\prime}}{\partial \mathrm{z}}+\mathrm{K}_{\mathrm{m}}\left(\frac{\partial^{2} \mathrm{w}}{\partial \mathrm{x}_{\mathrm{i}}^{2}}\right)+\mathrm{g} \frac{\theta(\mathrm{z})}{\theta_{\mathrm{r}} \mathrm{ef}(\mathrm{z})}-\mathrm{S}_{\mathrm{w}}
\end{aligned}
$$

...where, $\mathrm{K}_{\mathrm{m}}$ and $\mathrm{p}^{\prime}$ represent the local exchange coefficient and pressure perturbation parameter, respectively. The Coriolis parameter $\mathrm{f}$ describes the rotation of near-surface wind compared to the geostrophic wind components $\mathrm{u}_{\mathrm{g}}$ and $\mathrm{v}_{\mathrm{g}} \cdot \mathrm{S}_{\mathrm{u}}, \mathrm{S}_{\mathrm{v}}$ and $\mathrm{S}_{\mathrm{w}}$ are local source/sink terms that model the wind drag of semi-permeable obstacles. When air flows through a porous body a pressure gradient along the direction $\mathrm{i}$ of the wind component $\mathrm{u}_{\mathrm{i}}\left(\mathrm{u}_{\mathrm{i}}=\mathrm{u}, \mathrm{v}, \mathrm{W}\right.$ and $\left.\mathrm{i}=1,2,3\right)$ is generated [26].

Continuous equation:

$$
\frac{\partial u}{\partial x}+\frac{\partial v}{\partial y}+\frac{\partial w}{\partial z}=0
$$

Atmospheric turbulence:

$$
\begin{gathered}
\frac{\partial \mathrm{E}}{\partial \mathrm{t}}+\mathrm{u}_{\mathrm{i}} \frac{\partial \mathrm{E}}{\partial \mathrm{x}_{\mathrm{i}}}=\mathrm{K}_{\mathrm{E}}\left(\frac{\partial^{2} \mathrm{E}}{\partial \mathrm{x}_{\mathrm{i}}^{2}}\right)+\operatorname{Pr}-\mathrm{Th}+\mathrm{Q}_{\mathrm{E}}-\varepsilon \\
\frac{\partial \epsilon}{\partial \mathrm{t}}+\mathrm{u}_{\mathrm{i}} \frac{\partial \epsilon}{\partial \mathrm{x}_{\mathrm{i}}}=\mathrm{K}_{\epsilon}\left(\frac{\partial^{2} \epsilon}{\partial \mathrm{x}_{\mathrm{i}}^{2}}\right)+\mathrm{c}_{1} \frac{\epsilon}{\mathrm{E}} \operatorname{Pr}-\mathrm{c}_{3} \frac{\epsilon}{\mathrm{E}} \operatorname{Th}-\mathrm{c}_{2} \frac{\epsilon^{2}}{\mathrm{E}}+\mathrm{Q}_{\epsilon}
\end{gathered}
$$

...where, $\mathrm{K}$ is the exchange coefficient, $\mathrm{Q}$ determines the exchange conditions between air and vegetation, E represents turbulence, $\varepsilon$ represents dissipation, $\mathrm{c}_{1}, \mathrm{c}_{2}$ and $\mathrm{c}_{3}$ are empirical constants, $\mathrm{c}_{1}=1.44, \mathrm{c}_{2}=1.92$ and $\mathrm{c}_{3}=1.44$. $\mathrm{Pr}$ and $\mathrm{Th}$ denote the production and dissipation of turbulent energy caused by wind shearing (Pr) and thermal stratification (Th) [26].

Using the high-tech zone (Fig. 1c) as the simulation area, the 3D model of the study area was established using ENVI-met. Table 2 lists the main input parameters of the model simulation.

The accuracy of the model was evaluated using the root mean square error (RMSE) and mean absolute percentage error (MAPE), as shown in Eqs. (3) and (4), respectively:

$$
R M S E=\sqrt{\frac{\sum_{i=1}^{n}\left(x_{i}-x_{i}^{\prime}\right)^{2}}{n}}
$$


Table 2. Main input parameters of model simulation.

\begin{tabular}{|c|c|c|}
\hline & Input parameters & Value \\
\hline \multirow{3}{*}{$\begin{array}{c}\text { Model } \\
\text { parameter } \\
\text { setting }\end{array}$} & Simulation start date & $\begin{array}{c}2019.6 .13 \text { (total } \\
\text { simulation } 24 \mathrm{~h} \text { ) }\end{array}$ \\
\cline { 2 - 3 } & Minimum temperature & $22^{\circ} \mathrm{C}$ (at 4:00) \\
\cline { 2 - 3 } & Maximum temperature & $33^{\circ} \mathrm{C}$ (at 14:00) \\
\hline \multirow{2}{*}{$\begin{array}{c}\text { Initial } \\
\text { parameter } \\
\text { setting }\end{array}$} & $\begin{array}{c}\text { Minimum relative } \\
\text { humidity }\end{array}$ & $10 \%$ (at 14:00) \\
\cline { 2 - 3 } & $\begin{array}{c}\text { Maximum relative } \\
\text { humidity }\end{array}$ & $35 \%$ (at 6:00) \\
\cline { 2 - 3 } & $\begin{array}{c}\text { Wind speed } 10 \mathrm{~m} \text { above } \\
\text { ground }\end{array}$ & $2.5 \mathrm{~m} / \mathrm{s}$ \\
\cline { 2 - 3 } & Wind direction & East wind \\
\hline
\end{tabular}

$$
M A P E=\frac{1}{n} \sum_{i=1}^{n} \frac{\left|x_{i}-x_{i}^{\prime}\right|}{x_{i}} \times 100 \%
$$

...where $x_{i}$ is analog value, $x_{i}^{\prime}$ is measured value, $n$ is number of observations, and RMSE and MAPE reflect the magnitude of simulation accuracy and prediction effect, respectively.

\section{Correlation Analysis}

The correlations between the urban thermal environment and urban spatial morphological parameters are determined using the Spearman's correlation coefficients. The Spearman's coefficient is used to measure the linear correlation between the ordered variables and is considered the Pearson correlation coefficient between the sorted variables. As the data is non-numeric, the original data $\left(\mathrm{x}_{\mathrm{i}}, \mathrm{y}_{\mathrm{i}}\right)$ cannot be directly used, but using the quality of the data, the range of values is limited to between 1 and $\mathrm{n}$ [28], where $r_{s}$ represents the Spearman's correlation coefficient, $U_{i}$ and $V_{i}$ represent the quality of the variables $x_{i}$ and $y_{i}$, respectively, and $D_{i}$ represents the quality difference. The equations are as follows:

$$
\begin{gathered}
r_{s}=1-\frac{6 \sum_{i=1}^{n} D_{i}^{2}}{n\left(n^{2}-1\right)} \\
D_{i}=U_{i}-V_{i}
\end{gathered}
$$

\section{Results and Discussion}

\section{Model Accuracy Assessment}

The measured temperature data is the meteorological data at a pedestrian height of approximately $1.5 \mathrm{~m}$. Using ENVI-met to simulate the temperature distribution of the study area, the temperature data of the monitoring points with the same height as the measured data were

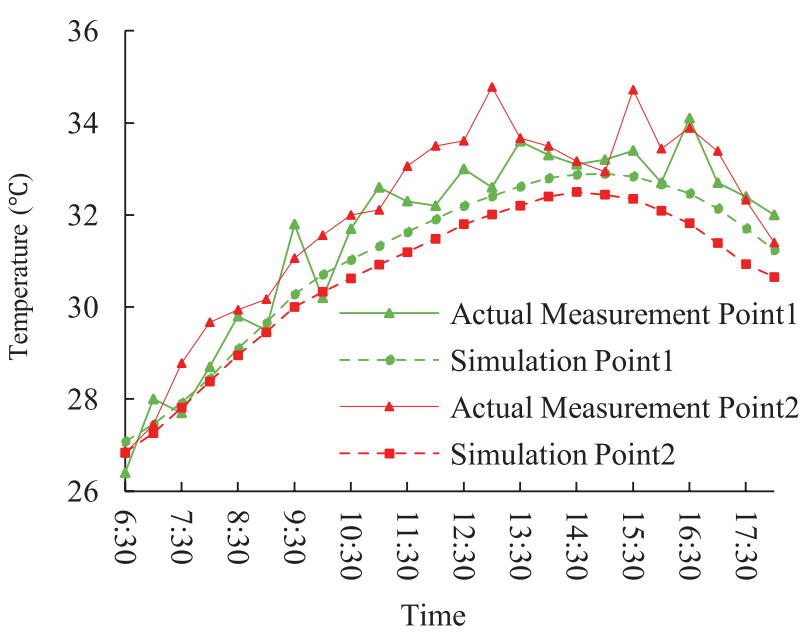

Fig. 2. Comparison between measured data and simulated data of monitoring points in study area.

selected for comparative analysis. It can be seen from Fig. 2 that the simulated temperature curve agrees well with the measured temperature curve. The RMSE of monitoring point 1 was $0.73{ }^{\circ} \mathrm{C}$ and MAPE was $1.92 \%$. Monitoring point 2 is located on the side of the road and is significantly affected by pedestrians and vehicles, and hence, the MAPE is $3.75 \%$. The correlation coefficient $\mathrm{R}^{2}$ between the measured values of the monitoring points 1 and 2 and the simulated values are 0.937 and 0.935 , respectively, indicating high correlations. Existing research results show that the correlation coefficient $\mathrm{R}^{2}$ of the ENVI-met simulated temperature data and measured data is within the range 0.79-0.96, and the MAPE values of monitoring points 1 and 2 are both less than $5 \%$, indicating that the ENVI-met simulation results are reliable. The application of ENVI-met simulation to analyze urban microclimate environments is feasible. Middel et al. used ENVI-met to simulate the urban thermal environments of three communities in Phoenix, Arizona, USA, with RMSEs in the range $1.41-3.17^{\circ} \mathrm{C}$ [29]. Lao et al. simulated the outdoor thermal environment in a typical block in Zhongshan City, and found that the RMSE was $0.31-0.52^{\circ} \mathrm{C}$ and MAPE was $0.77-1.25 \%$ [30]. Lu et al. considered ENVImet suitable for medium- and small-scale microclimate environment simulations and did not verify the accuracy when simulating the microclimate environment in the North Xi'an area [31].

Table 3. Quantitative evaluation of simulation results of ENVImet model.

\begin{tabular}{|c|c|c|c|}
\hline \multirow{2}{*}{ Temperature } & \multicolumn{3}{|c|}{ Evaluation index } \\
\cline { 2 - 4 } & $\mathrm{RMSE} /{ }^{\circ} \mathrm{C}$ & $\mathrm{MAPE} / \%$ & $\begin{array}{c}\text { Correlation } \\
\text { coefficient }\left(\mathrm{R}^{2}\right)\end{array}$ \\
\hline $\begin{array}{c}\text { Monitoring } \\
\text { point } 1\end{array}$ & 0.73 & 1.92 & 0.937 \\
\hline $\begin{array}{c}\text { Monitoring } \\
\text { point 2 }\end{array}$ & 1.35 & 3.75 & 0.935 \\
\hline
\end{tabular}




\section{Spatial Dependencies of UMP-T Relationships}

Fig. 3 shows the Spearman's coefficients between the UMPs and $\mathrm{T}_{\mathrm{a}}$ for the statistical units of $20 \mathrm{~m} \times 20 \mathrm{~m}$, $50 \mathrm{~m} \times 50 \mathrm{~m}$, and $100 \mathrm{~m} \times 100 \mathrm{~m}$ (model simulation grid resolution is $10 \mathrm{~m} \times 10 \mathrm{~m} \times 5 \mathrm{~m}$ ). The results show that the Spearman's correlation coefficients of BCR (Fig. 3a) and SCD (Fig. 3f) with $\mathrm{T}_{\mathrm{a}}$ increase with distance from the ground at all three spatial scales. When the distance from the ground is higher than
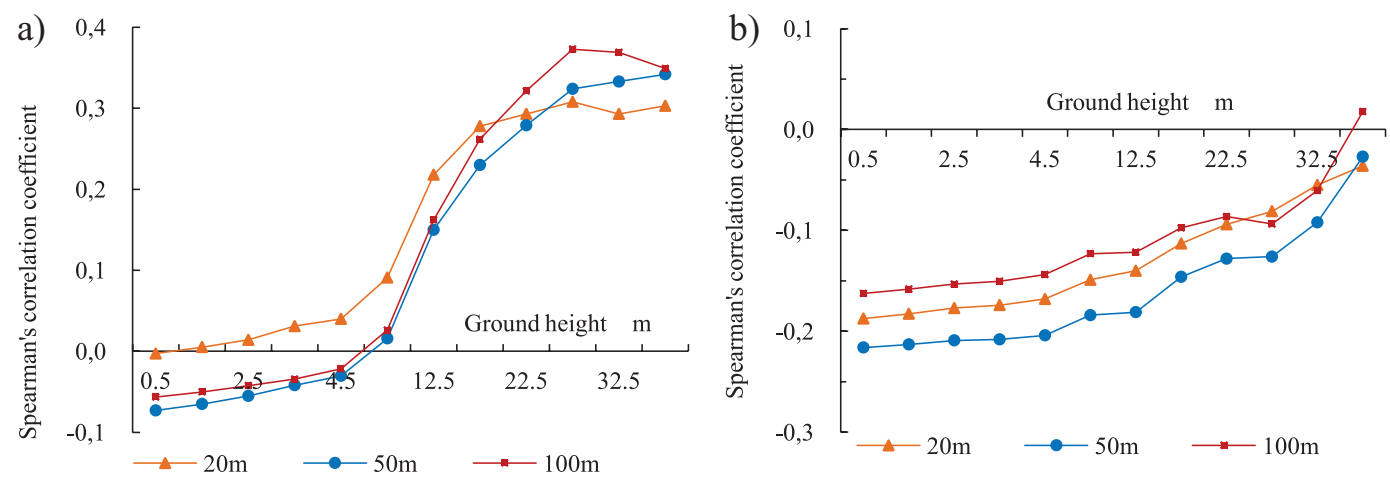

c)

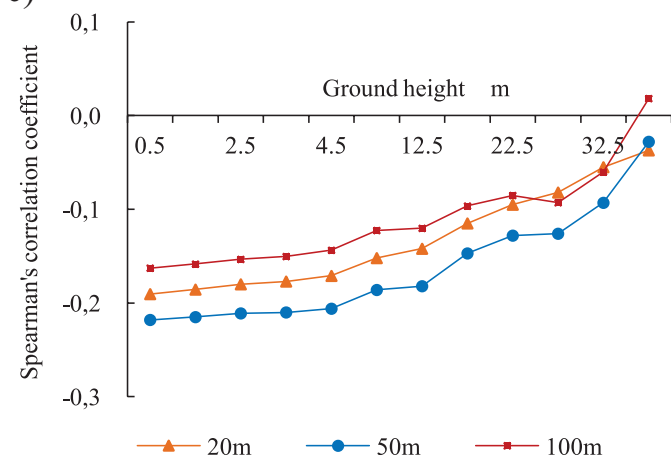

d)

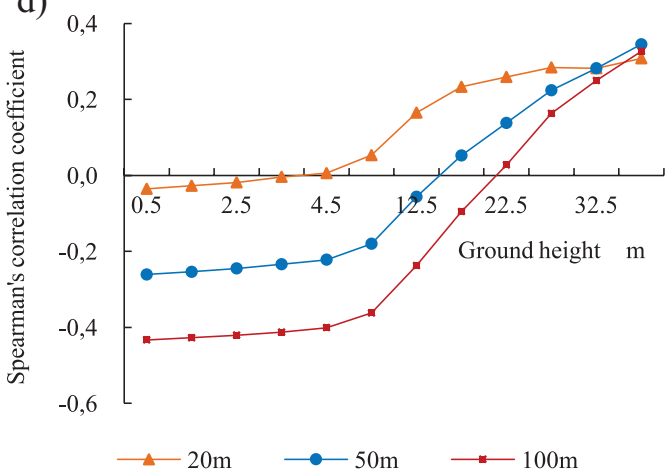

e)

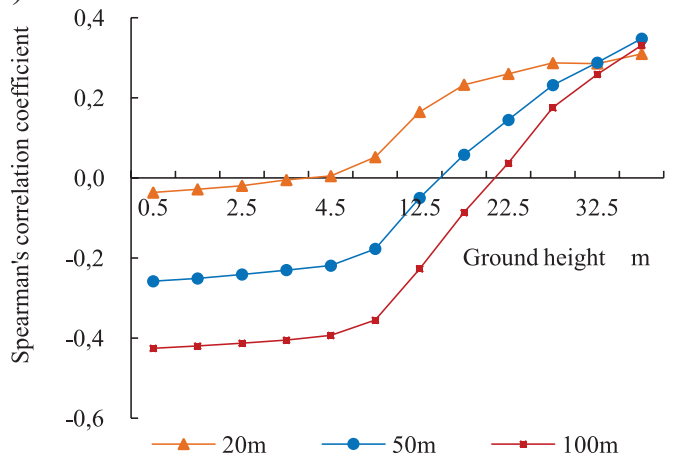

f)

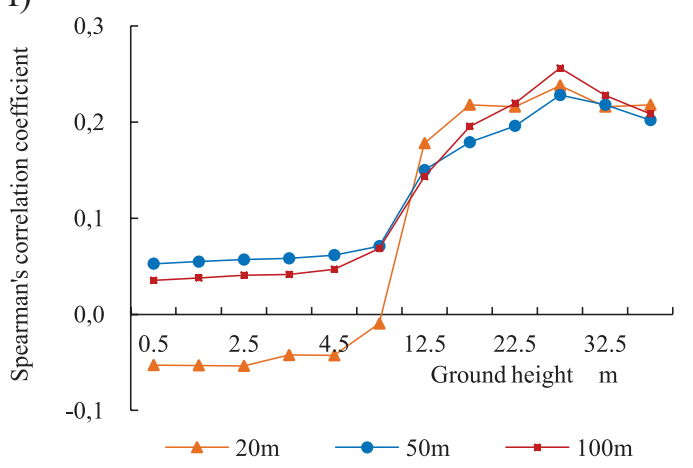

g)

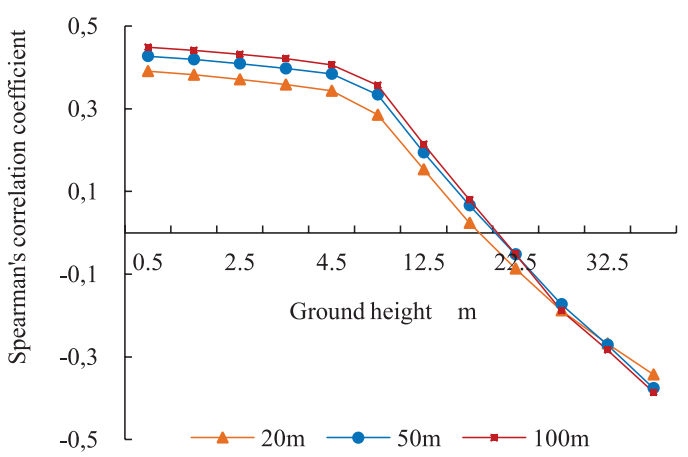

Fig. 3. Spearman's correlation coefficients between UMPs and thermal environment at different spatial scales. a) BCR, b) GCR, c) Vegetation fraction, d) Floor area ratio, e) Cubic index, f) Space crowded degree, g) Sky view factor. 
$12.5 \mathrm{~m}$, the positive correlation reaches a confidence level of 0.05 . Among these, the correlation coefficients are the highest at the $100 \mathrm{~m} \times 100 \mathrm{~m}$ spatial scale, reaching 0.37 and 0.26 for BCR and SCD, respectively. The Spearman's correlation coefficients of FAR (Fig. 3d) and cubic index (Fig. 3e) with $\mathrm{T}_{\mathrm{a}}$ are at the scales of $50 \mathrm{~m} \times 50 \mathrm{~m}$ and $100 \mathrm{~m} \times 100 \mathrm{~m}$. At a height of $12.5 \mathrm{~m}$, there is a significant negative correlation at the 0.05 confidence level. At heights exceeding $17.5 \mathrm{~m}$ and $27.5 \mathrm{~m}$ from the ground, there is a significant positive correlation. Among these, the correlation coefficient is the highest at the $50 \mathrm{~m} \times 50 \mathrm{~m}$ spatial scale and reaches 0.35 . Due to the large difference between the simulated temperature of the building and the surrounding temperature, the abnormal temperature value at each height is eliminated. When the distance from the ground is less than $12.5 \mathrm{~m}$, there are many grids of buildings, and there are many abnormal temperature values that need to be eliminated. Therefore, the four indicators related to building distribution, BCR, FAR, SCD, and cubic index, have low correlation with temperature. When the distance from the ground is more than $12.5 \mathrm{~m}$, the number of grids of buildings gradually decreases, and the abnormal temperature values that need to be eliminated decrease accordingly, and the correlation between the four indicators and the temperature also shows an upward trend.

In contrast, the Spearman's correlation coefficients of relative area of grass (Fig. 3b) and vegetation fraction (Fig. 3c) with $\mathrm{T}_{\mathrm{a}}$ at the three spatial scales decrease with height from the ground. When the height from the ground is greater than $12.5 \mathrm{~m}$, the correlation is not significant at the spatial scale of $100 \mathrm{~m} \times 100 \mathrm{~m}$.

However, it can reach -0.22 at the spatial scale of $50 \mathrm{~m} \times 50 \mathrm{~m}$. The Spearman's correlation coefficient of SVF and T decreases with increase in height from the ground. When the height is lower than $12.5 \mathrm{~m}$, there is a significant positive correlation. When the height exceeds $27.5 \mathrm{~m}$, there is a significant negative correlation at the 0.05 confidence level. Among the seven UMPs, the FAR and cubic index are the most affected by the spatial scale. Taking a distance of $3.5 \mathrm{~m}$ from the ground as an example, the correlation coefficients between cubic index and $\mathrm{T}_{\mathrm{a}}$ are $-0.01,-0.23$, and -0.41 at the scales of $20 \mathrm{~m} \times 20 \mathrm{~m}, 50 \mathrm{~m} \times 50 \mathrm{~m}$, and $100 \mathrm{~m} \times 100 \mathrm{~m}$, respectively. In comparison, the SVF index is less affected by the spatial scale. Existing research shows that the relationship between SVF and surface temperature is mainly negative [32]. Berger et al. studied the effect of SVF in Berlin and Cologne on the surface temperature during the four seasons, and found that the larger the SVF, the lower the surface temperature [21]. However, some studies have shown that the two factors are significantly positively correlated. For instance, Yan et al. determined that the increase in SVF increases the daytime temperature [33]. Land Use-type Dependencies of UMP-T Relationships

The study area includes residential land, commercial land, green space, roads, and other land use types.

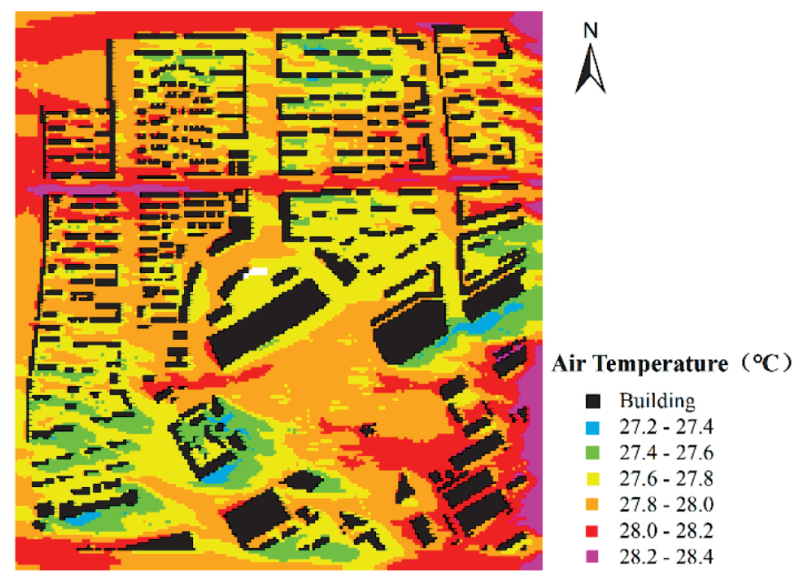

Fig. 4. Distribution of temperature field in study area.

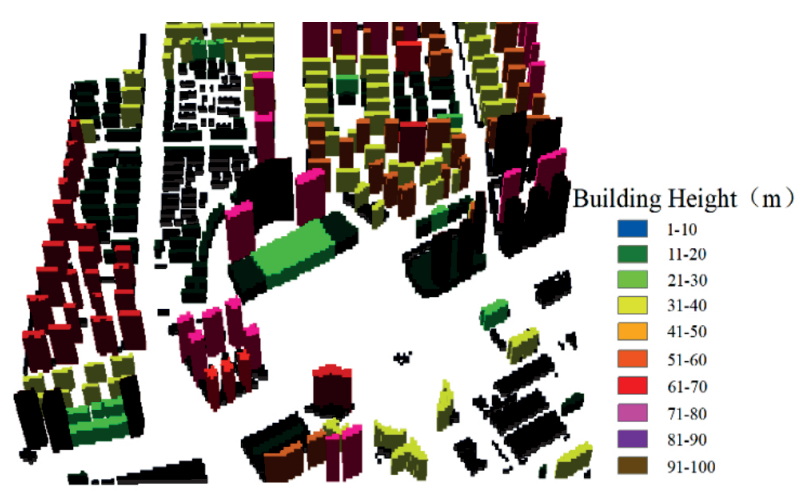

Fig. 5. Distribution of building height in study area.

The building heights in the study area are in the range 3-91 $\mathrm{m}$, and the urban thermal environment and 3D morphology of the city are complicated (Figs 4 and 5). At 10:00 a.m. in June, the solar altitude angle is approximately $58^{\circ}$. The shade effect of the building at this time is a key factor affecting the urban temperature. The Spearman's correlation coefficients of the UMPs and $T_{a}$ for residential land, commercial land, and the entire study area were calculated on a $20 \mathrm{~m} \times 20 \mathrm{~m}$ spatial scale. When the height from the ground is lower than $22.5 \mathrm{~m}$, except for the SCD of the residential land, the correlations of all other parameters reach a confidence level of 0.05 . When the height from the ground is lower than $12.5 \mathrm{~m}$, the BCR of commercial land (Fig. 6a) has no significant correlation with $T_{a}$. However, the FAR (Fig. 6d) and cubic index (Fig. 6e) are significantly negatively correlated with $\mathrm{T}_{\mathrm{a}}$ at the 0.05 confidence level. At this time, $\mathrm{T}_{\mathrm{a}}$ is mainly affected by the shadow of the building. When the height from the ground is higher than $12.5 \mathrm{~m}$, the correlations between $\mathrm{T}_{\mathrm{a}}$ and BCR (Fig. 6a), GCR (Fig. 6b), FAR (Fig. 6d), and SCD (Fig. 6f) of commercial land suddenly increase. At this time, the shade effect of the building is weakened, and the peak values of BCR, GCR, vegetation fraction, and SCD appear near $17.5 \mathrm{~m}$, and are $0.47,-0.3,-0.3$, and 0.59 , respectively. When the 
height is lower than $12.5 \mathrm{~m}$, the correlation between the spatial morphological parameters of residential land and $\mathrm{T}$ is higher than that of commercial land, except for SCD (Fig. 6f). This may be because commercial land buildings are mainly high-rise buildings, with high land use efficiency, less vegetation, and mostly lawns. The GCR and vegetation fraction have similar effects on the thermal environment. The Spearman's correlation coefficient between the SCD of residential land and $\mathrm{T}_{\mathrm{a}}$ changes from a significant negative correlation to
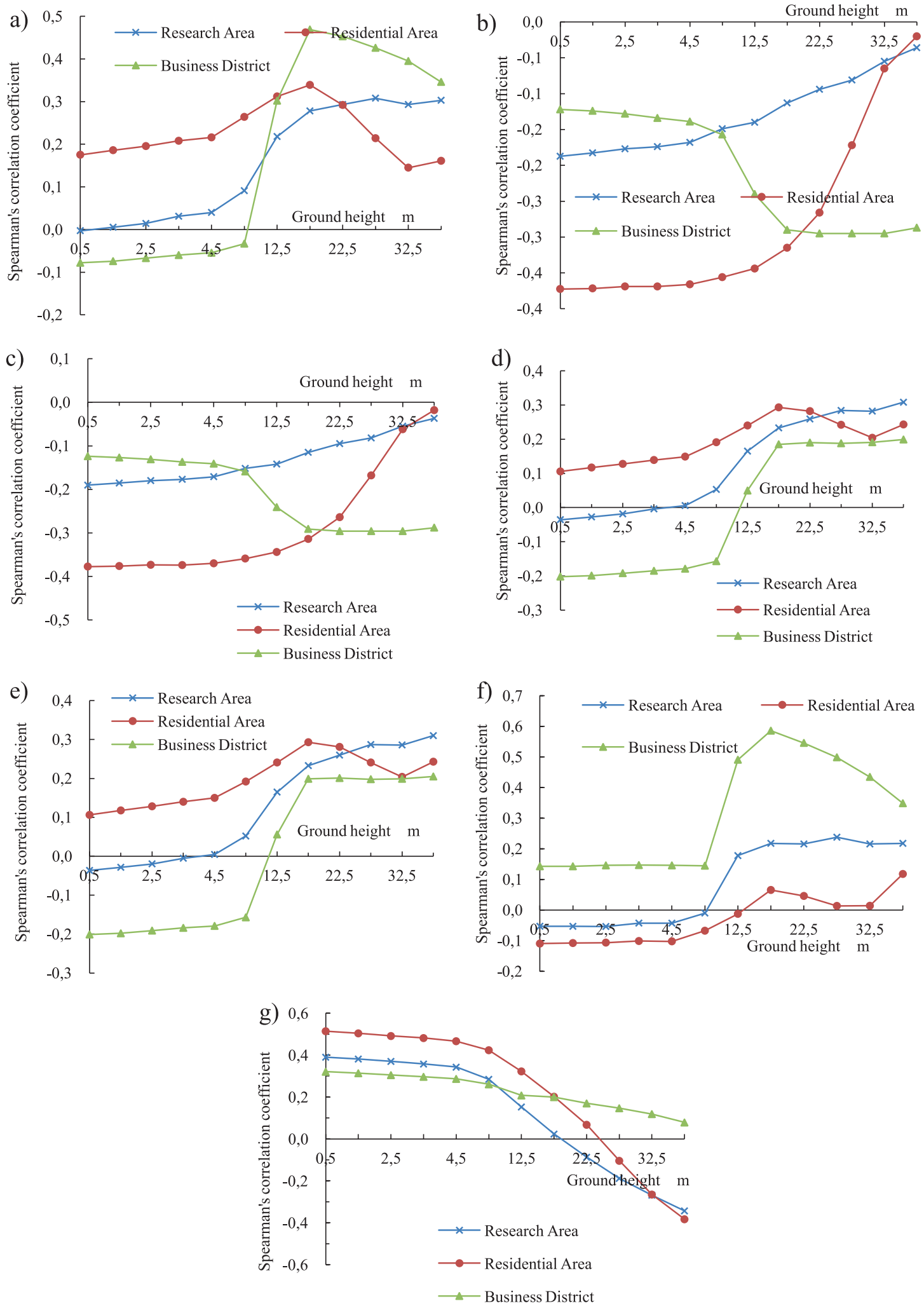

Fig. 6. Spearman's correlation coefficients between UMPs and thermal environment under different land use types. a) BCR, b) GCR, c) Vegetation fraction, d) Floor area ratio, e) Cubic index,f) Space crowded degree, g) Sky view factor. 


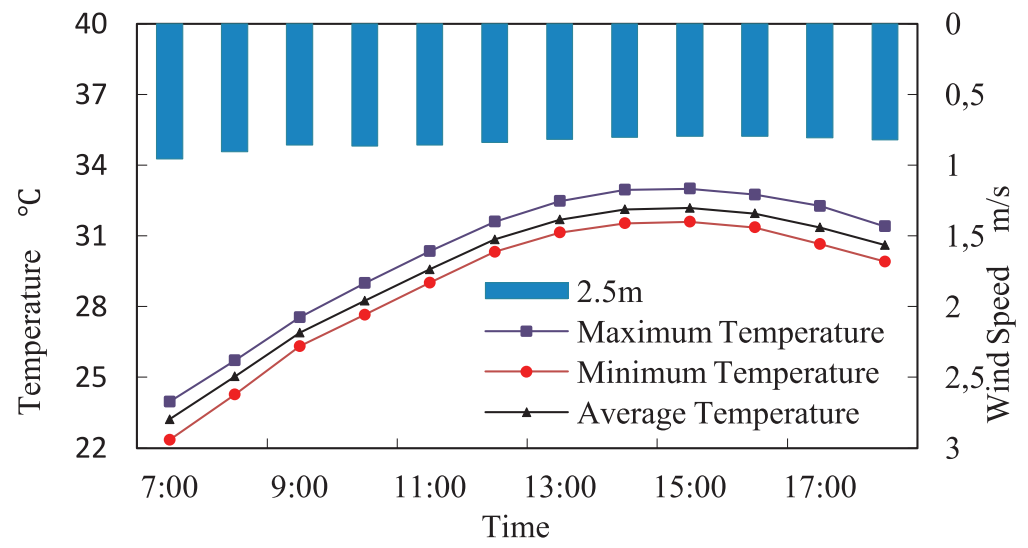

Fig. 7. Simulation data of meteorological values in residential areas.

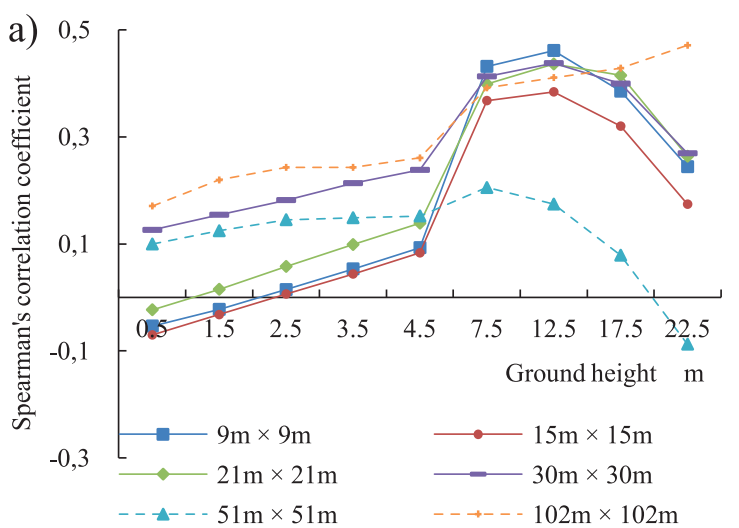

c)
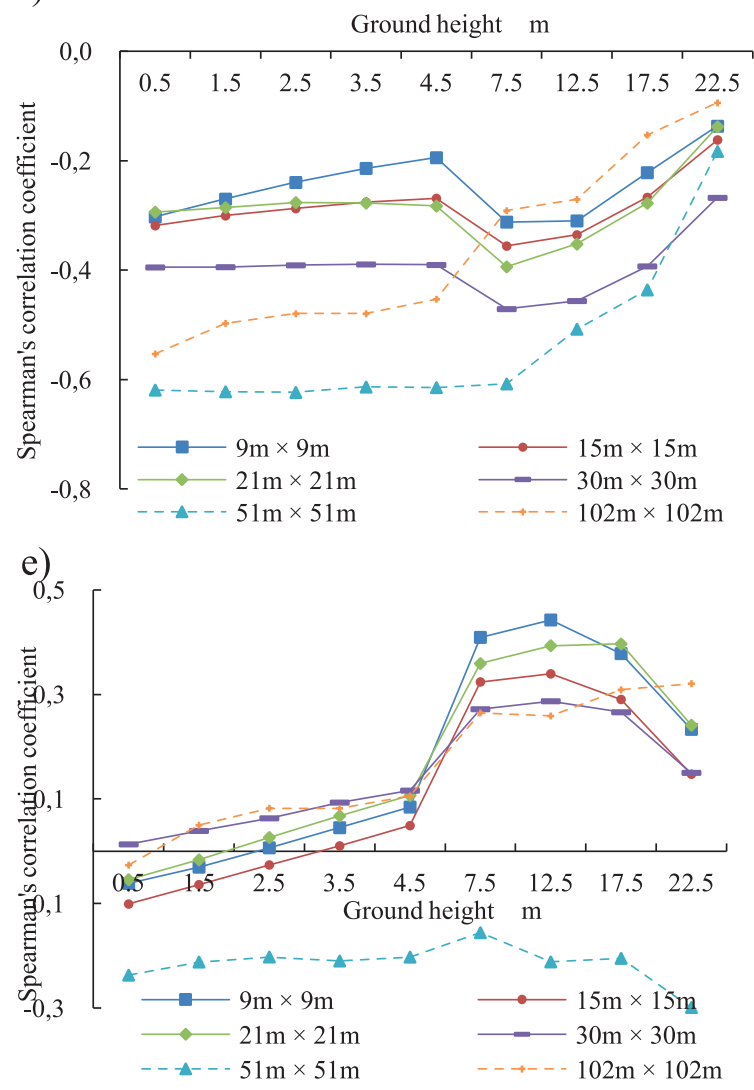

b) Ground height $\mathrm{m}$

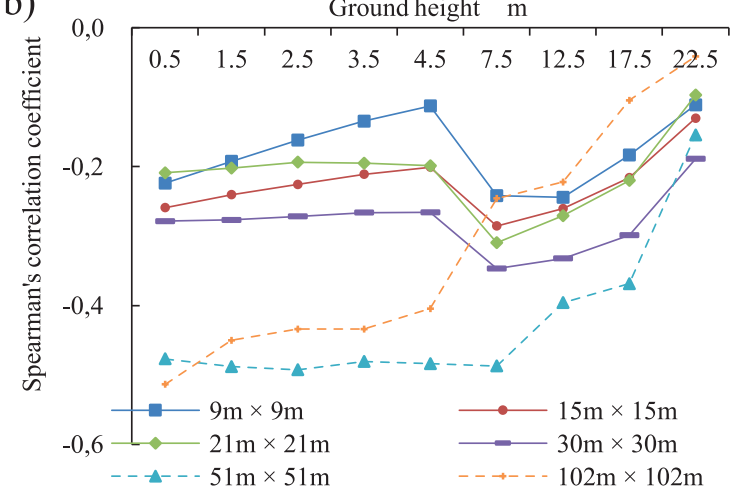

d)
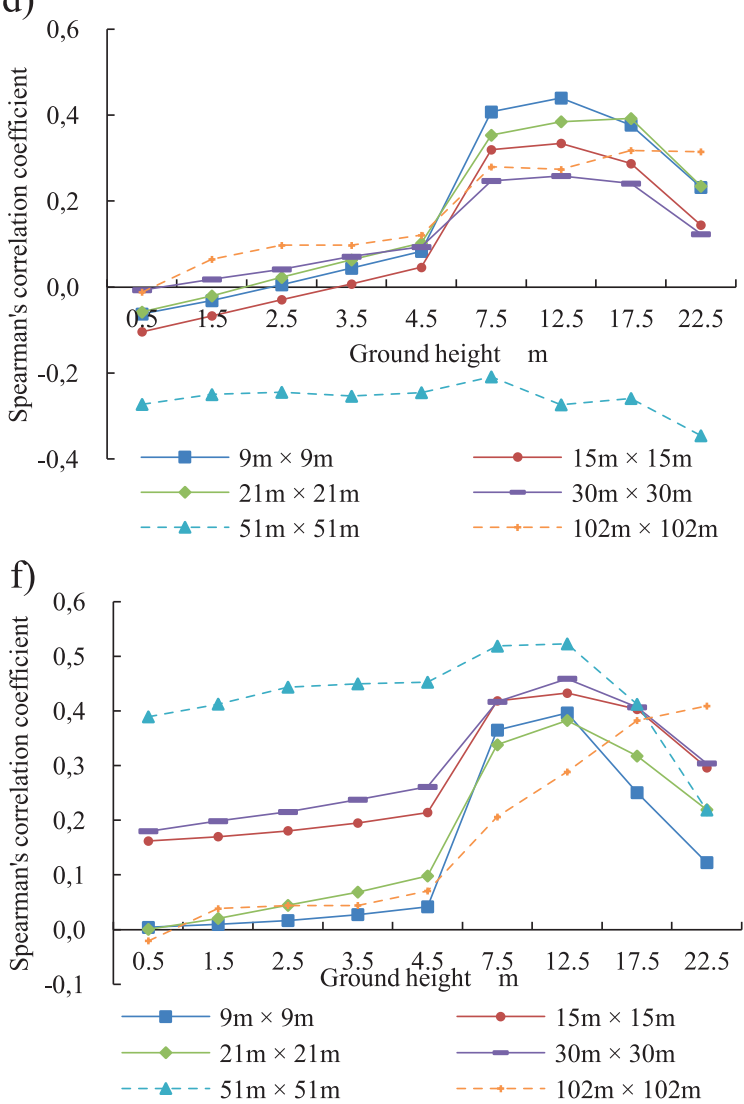

Fig. 8. Spearman's correlation coefficients between UMPs and thermal environment at different spatial scales. a) BCR, b) GCR, c) Vegetation fraction, d) Floor area ratio, e) Cubic index, f) Space crowded degree 
an irrelevance with increase in height. This is related to the model grid resolution. When the network resolution is $10 \mathrm{~m} \times 10 \mathrm{~m} \times 5 \mathrm{~m}$, the vegetation canopy is ignored to a certain extent, resulting in extremely high information repetition rates between the GCR and vegetation fraction. In mathematical statistics, some spatial morphological indices and thermal environment have scale relationships.

\section{UMP-T Relationships of Typical Residential Land}

In view of the various types of land in the study area, differences in building heights, and the complex urban thermal environment and 3D morphology of the city, we conducted a thorough study using a typical residential land as the study area (Fig. 1b). The grid resolution of the ENVI-met model was set to $3 \mathrm{~m} \times$ $3 \mathrm{~m} \times 5 \mathrm{~m}$ for fine simulation. Considering the sampling scales at each level, the multi-scale spatial statistical units of this study were $9 \mathrm{~m} \times 9 \mathrm{~m}, 15 \mathrm{~m} \times 15 \mathrm{~m}$, $21 \mathrm{~m} \times 21 \mathrm{~m}, 30 \mathrm{~m} \times 30 \mathrm{~m}, 51 \mathrm{~m} \times 51 \mathrm{~m}$, and $102 \mathrm{~m} \times 102 \mathrm{~m}$. The average daily temperature in this area is $29.5^{\circ} \mathrm{C}$, and the average temperature difference at the same time is $1.4^{\circ} \mathrm{C}$. The daytime wind environment is relatively stable with an average wind speed of approximately $0.84 \mathrm{~m} / \mathrm{s}$, and hence the influence of the wind environment on the thermal environment can be excluded (Fig. 7).

The Spearman's correlation coefficients of BCR (Fig. 8a), FAR (Fig. 8d), and cubic index (Fig. 8e) with $\mathrm{T}_{\mathrm{a}}$ have no significant correlation in the space of $51 \mathrm{~m} \times 51 \mathrm{~m}$ and $102 \mathrm{~m} \times 102 \mathrm{~m}$. At a spatial scale of $9 \mathrm{~m} \times 9 \mathrm{~m}$, the correlations reach a confidence level of 0.05 when the height above the ground is $4.5 \mathrm{~m}$, and the values for BCR, FAR and cubic index reach $0.46,0.44$, and 0.44 , respectively. The correlations of GCR (Fig. 8b), vegetation fraction (Fig. 8c), and SVF Fig. $8 \mathrm{~g}$ ) with $\mathrm{T}_{\mathrm{a}}$ at heights lower than $22.5 \mathrm{~m}$ above the ground reach a confidence level of 0.05 . Among these, the correlation was highest at the spatial scale of $51 \mathrm{~m} \times 51 \mathrm{~m}$, reaching $-0.49,-0.62$, and 0.82 , respectively, for GCR, vegetation fraction, and SVF with $\mathrm{T}_{\mathrm{a}}$. However, as the spatial scale increases to $102 \mathrm{~m} \times 102 \mathrm{~m}$, the correlations are only significantly relevant at heights lower than $1.5 \mathrm{~m}$ from the ground. Comparing the selected 2D and 3D morphological parameters, SVF can comprehensively characterize the internal structure of the city. This is because it integrates information such as building height, BCR, and vegetation height. Hence, it has a significant impact on the urban thermal environment and the highest correlation with $T_{a}$. The correlations between the UMPs and $T_{a}$ are significantly affected by the model grid resolution and spatial scale, i.e., the statistical analysis unit. Compared with the simulation grid resolution of $10 \mathrm{~m} \times 10 \mathrm{~m} \times 5 \mathrm{~m}$ in Section 3.2, the vegetation fraction under the condition of $3 \mathrm{~m} \times 3 \mathrm{~m} \times 5 \mathrm{~m}$ can consider the projection area of the canopy, and hence, its correlation with $\mathrm{T}_{\mathrm{a}}$ is higher than that of GCR. The 3D morphology adds height information on the basis of the 2D pattern parameters. Generally, the impact of $\mathrm{BCR}$ and cubic index on the thermal environment is more significant [34], but the Spearman's correlation coefficient between BCR and $\mathrm{T}_{\mathrm{a}}$ is always higher than that between the cubic index and $T_{a}$. Berger et al. obtained the surface temperature data through Landsat ETM+ [21]. The correlation between the 2D parameters obtained was mostly higher than that between the $3 \mathrm{D}$ parameters. The authors believed that the maximum deviation of the zenith angle between the airborne ETM + sensor and the city edge when viewing the city was $7.4^{\circ}$. As a result, the horizontal city surface was oversampled, and finally the 2D parameters were more closely related to the morphological parameters than the $3 \mathrm{D}$ parameters were. The $3 \mathrm{D}$ urban environment obtained in the simulated environment in the present study compensates for the defects of Berger's horizontal urban surface being oversampled and vertical urban surface being undersampled.

\section{Conclusions}

In this study, numerical simulation and GIS methods were combined to simulate the thermal environment. The grid resolutions are $10 \mathrm{~m} \times 10 \mathrm{~m} \times 5 \mathrm{~m}$ and $3 \mathrm{~m} \times 3 \mathrm{~m} \times 5 \mathrm{~m}$, respectively, which are used to simulate and analyze the urban thermal environment of the study area and its residential areas. And calculate the Spearman correlation coefficient between UMP and Ta under different spatial scales. The main conclusions are as follows:

In the vertical direction, the correlations of the UMPs with $T_{\text {a }}$ are closely related to vegetation height and building height. The shade effect of buildings is the key factor affecting urban temperature. The 3D morphologies of vegetation and buildings have different influences on the temperature. At heights greater than $12.5 \mathrm{~m}$, the BCR and SCD have significant positive correlations with $\mathrm{T}_{\mathrm{a}}$. At heights lower than $12.5 \mathrm{~m}$, the GCR and vegetation fraction have significant negative correlations with $\mathrm{T}_{\mathrm{a}}$.

The correlations between the UMPs and $\mathrm{T}_{\mathrm{a}}$ are significantly affected by the grid resolution and spatial scale of the model, i.e., the statistical analysis unit. As the spatial scale increases, the FAR and cubic index are no longer related to $T_{a}$. When the grid resolution of the model is large, the information repetition rate between the GCR and vegetation fraction is high, and the difference between their influences on $\mathrm{T}_{\mathrm{a}}$ is not evident.

Among the urban spatial morphological indices, 3D SVF has the highest correlation with $\mathrm{T}_{\mathrm{a}}$. The cubic index, SCD, BCR, and FAR show significant positive correlations with $\mathrm{T}_{\mathrm{a}}$. The vegetation fraction considers the projected area of the canopy and its performance is stronger than that of GCR. It shows a significant negative correlation with $\mathrm{T}_{\mathrm{a}}$. 


\section{Acknowledgments}

This work was supported by Shandong Natural Science Foundation (ZR2018MD0 08), the Open Research Funding Program of KLGIS (KLGIS2016A01) and the National Natural Science Foundation of China [4127 1413].

\section{Conflict of Interest}

The authors declare no conflicts of interest.

\section{References}

1. XIE P., WANG Y., LIU Y. Incorporating social vulnerability to assess population health risk due to heat stress in China. Acta Geographica Sinica, 70 (7), 1041, 2015 [In Chinese].

2. CHUN B., GULAMANN J.M. Spatial statistical analysis and simulation of the urban heat island in high-density central cities. Landscape and Urban Planning, 125, 76, 2014.

3. XIE Q., DUAN L., WANG Z. The impact of summer urban landscape pattern on the spatial distribution of thermal fields: Taking Wuhan as an example. Resources and Environment in the Yangtze River, 27 (08), 1735, 2018 [In Chinese].

4. ZHENG Z., ZHOU W., WANG J., HU X., QIAN Y. SixtyYear Changes in Residential Landscapes in Beijing: A Perspective from Both the Horizontal (2D) and Vertical (3D) Dimensions. Remote Sensing, 195, 1, 2017.

5. DING H., LI W. Analysis of Land Use Land Cover Temporal-spatial Distribution and Land Surface Temperature in Nanjin City Using TVX Method. Resources and Environment in the Yangtze Basin, 27 (04), 735, 2018 [In Chinese].

6. MORAKINYO T.E., LAU K.L., REN C., Ng E. Performance of Hong Kong's common trees species for outdoor temperature regulation, thermal comfort and energy saving. Building and Environment, 137, 157, 2018.

7. PAETH H., BORN K., GIRMES R., PODZUN R., JACOB D. Regional Climate Change in Tropical and Northern Africa due to Greenhouse Forcing and Land Use Changes. Journal of Climate, 22, 114, 2009.

8. LU F., XU D., CHENG Y., DONG S., GUO C., JIANG X., ZHENG X. Systematic review and meta-analysis of the adverse health effects of ambient PM2.5 and PM10 pollution in the Chinese population. Environmental Research, 136, 196, 2015.

9. SANTAMOURIS M. Recent progress on urban overheating and heat island research. Integrated assessment of the energy, environmental, vulnerability and health impact. Synergies with the global climate change. Energy and Buildings, 207, 109482, 2020.

10. SRIVANIT M., HOKAO K. The Influence of Urban Morphology Indicators on Summer Diurnal Range of Urban Climate in Bangkok Metropolitan Area, Thailand. International Journal of Civil and Environmental Engineering, 11 (5), 34, 2011.

11. XU H. Quantitative analysis on the relationship of urban impervious surface with other components of the urban ecosystem. Acta Ecologica Sinica, 29 (5), 2456, 2009 [In Chinese].

12. GIRIDHARAN R., GANESAN S., LAU S. Daytime urban heat island effect in high-rise and high-density residential developments in Hong Kong. Energy and Buildings, 36, 525, 2004.

13. KONG F., YAN W., ZHENG G.,YIN H.,CAVAN G., ZHAN W., ZHANG N. Retrieval of three-dimensional tree canopy and shade using terrestrial laser scanning (TLS) data to analyze the cooling effect of vegetation. Agricultural and Forest Meteorology, 217, 22, 2016.

14. DIRKSEN M, RONDA R.J, THEEUWES N E, et al. Sky view factor calculations and its application in urban heat island studies. Urban Climate, 30, 100498, 2019.

15. EDUSSURIYA P., CHAN A., Ye A. Urban morphology and air quality in dense residential environments in Hong Kong. Part I: District-level analysis. Atmospheric environment, 45, 4789, 2011.

16. YANG F., QIAN F., LAU S.S.Y. Urban form and density as indicators for summertime outdoor ventilation potential: A case study on high-rise housing in Shanghai. Building and Environment, 70, 122, 2013.

17. ZHAO C., FU G.B., LIU X., Fu F. Urban planning indicators, morphology and climate indicators: A case study for a north-south transect of Beijing, China. Building and Environment, 46, 1174, 2011.

18. HOVE L W A V, JACOBS C M J. Temporal and spatial variability of urban heat island and thermal comfort within the Rotterdam agglomeration. Building \& Environment, 50 (83), 91, 2015.

19. GIRIDHARAN R., LAU S.S.Y., GANESAN S., GIVONI B. Urban design factors influencing heat island intensity in high-rise high-density environments of Hong Kong. Building and Environment, 42, 3669, 2007.

20. ALI-TOUDERT F., MAYER H. Effects of asymmetry, galleries, overhanging façades and vegetation on thermal comfort in urban street canyons. Solar Energy, 81, 742, 2007.

21. BERGER C., ROSENTRETER J., VOLTERSEN M., BAUMGART C., SCHMULLIUS C., HESE S. Spatiotemporal analysis of the relationship between $2 \mathrm{D} / 3 \mathrm{D}$ urban site characteristics and land surface temperature. Remote Sensing of Environment, 193, 225, 2017.

22. TONG S., WONG N.H., JUSUF S.K., TAN C.L., WONG H.F., IGNATIUS M., TAN E. Study on correlation between air temperature and urban morphology parameters in built environment in northern China. Building and Environment, 127, 239, 2018.

23. JINAN MUNICIPAL BUREAU OF STATISTICS. Jinan statistical yearbook; China Statistics Press: Beijing, pp. 5-229, 2019 [In Chinese].

24. ZHANG P., HU Y. Three-dimensional architectural landscape changes at different spatial scales. Chinese Journal of Ecology, 32 (05), 1319, 2013.

25. OKE T.R., Canyon geometry and the nocturnal Urban heat island: Comparison of scale model and field observations. International Journal of Climatology, 1, 237, 1981.

26. BRUSE M., FLEER H. Simulating surface-plant-air interactions inside urban environments with a three dimensional numerical model. Environmental Modelling and Software, 13, 373, 1998.

27. MELLOR G.L., YAMADA T. Development of a turbulence closure model for geophysical fluid problems. Reviews of Geophysics and Space Physics, 20, 851, 1982. 
28. SPEARMAN C. The proof and measurement of association between two things. The American Journal of Psychology, 100 (3), 441, 1987.

29. MIDDEL A., HAB K., BRAZEL A.J. Impact of urban form and design on mid-afternoon microclimate in Phoenix Local Climate Zones. Landscape and Urban Planning, 122, 16, 2014.

30. LAO Z., LI Y., DENG X.J. Numerical simulation of outdoor thermal environment in Zhongshan City based on ENVI-met. China Environmental Science, 37 (09), 3523, 2017 [In Chinese].

31. LU X., YANG X. Urban Renewal Research Based on Microclimate Simulation and Thermal Comfort Experience
Based on ENVI-met Software: A Case Study of North Xin'an District, Shijingshan, Beijing. Urban Development Research, 25 (04), 147, 2018 [In Chinese].

32. ZHOU W., TIAN Y. Effects of urban three-dimensional morphology on thermal environment: a review. Acta Ecologica Sinica, 2, 1, 2019 [In Chinese].

33. YAN H., FAN S., GUO C.,WU F., ZHANG N., DONG L. Assessing the effects of landscape design parameters on intra-urban air temperature variability: The case of Beijing, China. Building and Environment, 76, 44, 2014.

34. UNGER J. Intra-urban relationship between surface geometry and urban heat island: review and new approach. Climate Research, 27, 253, 2004. 